\title{
Teachers' Self-efficacy and Performance in Teaching Literature in the Interest-based Classes at Senior High School
}

\author{
Nurindah \\ Universitas Negeri Makassar, Jln. Bonto Langkasa, Kampus Gunung Sari, Makassar, South Sulawesi, Indonesia \\ Mansyur Akil \\ Universitas Negeri Makassar, Jln. Bonto Langkasa, Kampus Gunung Sari, Makassar, South Sulawesi, Indonesia \\ Basri Jafar \\ Universitas Negeri Makassar, Jln. Bonto Langkasa, Kampus Gunung Sari, Makassar, South Sulawesi, Indonesia
}

\begin{abstract}
Teacher's self-efficacy is a specific phenomenon that can be seen as one of the contributors to the process of learning and effective teaching. Teacher self-efficacy was investigated at two Senior High Schools (SMAN 1 and SMAN 2) in Kendari, and proved its importance in the interest-based classes at senior high schools in Kendari. Findings revealed two major methods employed in the research study: 1) interviews conducted in the form of an open interview with 5 teachers; and 2) observation was focused on teachers teaching materials, classroom management, as well as the enthusiasm of the teacher during the learning process takes place. Based on the finding, this study argues that teachers have high confidence in their ability to teach literature because they ascribe high value to their performance. However, the self-efficacy of teachers did not have an impact when applied in practice. In the classroom observation, these elements generally did not show up. This shows that the dependence of teachers on textbooks is not accompanied by an increase in the ability of teachers to ask questions to the students during the learning process, so that the high self-efficacy of teachers does not produce learning achievement is high. This goal can be achieved by giving more opportunities and experiences for teachers to improve the quality of learning.
\end{abstract}

Index Terms - teachers' self-efficacy, performance, teaching literature, interest-based class

\section{INTRODUCTION}

Self-efficacy has become an important concept among educational researchers, since Albert Bandura introduced the concept in the 1970s through social learning theory. It is an individual's belief in his ability to perform a task or action required to achieve a particular result. The level of self-efficacy is different in every person (Bandura, 1997). In education, two kinds of self-efficacy matter. One is students' self-efficacy in relation to their own beliefs about their competence and performance, both actual and perceived, in specific content areas. The other is teachers' self-efficacy about their ability to impact change in student performance and achievement in the classroom. In fact, self-efficacy of teachers is a central phenomenon that can be seen as one of the contributors to the process of learning and effective teaching.

Teacher efficacy (short for teacher self-efficacy) has been associated with several factors of teaching effectiveness. For instance, research has noted impacts of teacher self-efficacy on rates of teacher retention and attrition (Billingsley, 2004). Teacher efficacy related to their classroom management has also been demonstrated as key to teacher burnout (Brouwers, A., \& Tomic, W. 2000); and teaching assistants' self-efficacy in teaching literature by it sources, personal assessments, and consequences (Mills, N., 2011).

One study investigated factors that contribute to special education teacher attrition and retention, Billingsley (2004) addresses four major themes: teacher characteristics and personal factors, teacher qualifications, work environments, and teachers' affective reactions to work. Problematic district and school factors lead to negative affective reactions to work which may lead to withdrawal and eventually attrition. It assumes that there are some teachers who remained calm and confident to face the problem that was happening so that they carried out their duties and responsibilities as usual.

Concerned with teachers' self-efficacy, Gibson and Dembo (1984) proved that the self-efficacy of teachers is a significant contributor to individual differences in the effectiveness of teaching. While Coladarci (1992) was concerned with the degree of teachers' sense of efficacy, as well as other hypothesized influences on commitment to teaching. It seems that the commitment of teachers has been considered an important factor in influencing teacher satisfaction and retention of teachers.

Furthermore, various teaching practices and teacher behavior can affect student performance (e.g., Tschannen-Moran, M., Hoy, A. W., \& Hoy, W. K. (1998); and Goddard, R. D., Hoy, W. K., \& Hoy, A. W. (2000). Accordingly, 
researchers have successfully documented how self-efficacy affects other constructs such as self attainment and learning achievement.

In class management, one study examined the direction and time-frame of relationships between perceived self efficacy in classroom management and the three dimensions of teacher burnout (Brouwers, A., \& Tomic, W. 2000). Henson (2001) asserted that teacher self-efficacy is an important variable which influences a teacher in selecting classroom management approaches. While, other researchers also proved the influence of self-efficacy of teachers to the elements of teaching for example, Pajares (1996) proved that the self-efficacy is closely related to the academic performances; Zimmerman, $(2000 ; 82)$ revealed that the self-efficacy was considered a highly effective predictor of students' motivation and learning. However, factors that might influence teaching practices and teacher behavior have received less attention in teaching literature.

More specifically in the context of education and schooling in Indonesia, 2013 curriculum incredibly emphasizes the activeness of learners in the learning and teaching process. The curriculum of the school emphasizes appreciation of the learner as a unique person. Learners are encouraged to have awareness as a part of an international community in participating as a world citizens (Chairani, 2015). It means that, the curriculum must be designed by giving opportunity to learners to improve the differences in skill and interest, one of them is the quality of teaching language and literature, both Indonesian and English, as the one of the curriculum needs to be addressed. It is the target of English learning and teaching in senior high school to enable the learners to use English language to communicate. In other words, the target is to make learners who are able to use English language functionally for their daily conversation both in oral and written form.

Therefore, the present study investigates teachers' self-efficacy in relation to New Curriculum recently implemented in Indonesia. This qualitative study examines the perspectives of five Indonesian teachers of literature regarding their own sense of teacher efficacy and their ability to deliver effective literature instruction within the New Curriculum frameworks. As such this study addresses the following questions: 1) How do teachers generally perceive their own teacher self-efficacy for teaching literature within the New Curriculum framework? 2) How are the teachers' selfefficacy related to their teaching experience? 3) How are the teachers' senses of self efficacy associated with their beliefs about students' ability?

\section{A. Significance of Teacher Efficacy in Teaching Literature in Indonesia}

The concept of self-efficacy comes from Western culture so that it may be different in interpretation when applied in teaching culture in Indonesia. Some statements in the self-efficacy instrument come from an instrument developed by researchers at Ohio State University. These instruments are used to measure self-efficacy and student learning outcomes that have been processed through a rigorous validation process. Thus, it is likely there will be a mismatch between the cultural aspects of self-efficacy in Indonesia. However, efforts to find and identify what was in the minds of teachers must still be done to improve the quality of teachers and the quality of student learning.

With growing insistence of education reform in Indonesia, teaching and teacher quality is a hot issue that must be addressed wisely. Teachers and schools are increasingly required to meet the standards of education. More specifically, in the context of education and schooling in Indonesia, the quality of teaching language and literature (both Indonesian and English) needs to be addressed. It has long been recognized that literature is an important factor in the development of quality human character and is even used as one indicator in determining the human development index (HDI). Therefore, the process of learning and appreciation of literature among students is one area that is interesting to study. Results of research and knowledge about the process can enrich our understanding of how teachers and students look at the importance of literature.

Literature-based learning, character and locality are very effectively implemented within the subjects of language and literature. Literature-based learning can improve students' ability to become better learners, and even become better readers and writers; it is more effectively to improve student learning through the writing narratives. In this case, literary learning requires students to be good readers, good listeners and good responders. This is what shapes the character of the students, with more formidable.

Teaching literature cannot be separated from the teaching of the language even though it seems their basic competencies are separately. In the Indonesian education, the term "language and literature" tends to be interpreted separately. The tendency often leads to proposals that language and literatures should be taught by different teachers. Based on the findings of Harras (2003), there are 91.6\% of respondents "agree" to separation of the literary languages with respect to the autonomy of teaching literature. This indicates that language and literature should separate.

Teaching literature is considered good and true when aesthetic perspective and an emphasis on the viewing angle is adopted. This is in line with the opinion of Rosenblatt, "To teach literature correctly is to emphasize the aesthetic stance and to de-emphasize the efferent." (1978, p.22-47). It means that students can not only identify what is contained in literary works such as background, character and characterization, as well as the storyline, but they can also identify what lies beyond the literary works such as the authorial intent, symbolism, narrative and so on.

\section{B. Self-efficacy}

Self-efficacy is a concept formulated by Bandura (1997), professor of psychology at Stanford University on social learning theory. According to Bandura (1997, p.3), "efficacy is a major base of action. People guide their lives by their 
beliefs of personal efficacy Self-efficacy refers to beliefs in one's capabilities to organize and execute the courses of action required to produce given attainments." Thus, this efficacy is the belief that encourages individuals to do and achieve something.

Self-efficacy is only one small part of the whole complex picture of human life, but it can provide a better understanding of life in terms of human capabilities. The diversity of human capabilities is recognized by the theory of self-efficacy. Self-efficacy theory is an attempt to understand the functioning of human life in self-control, setting the process of thinking, motivational, affective and psychological conditions (Bandura, 1997, p.36). Through this perspective, self-efficacy is believed to make people able to interpret and translate the factors internal and external to the action. However, it should be emphasized that different individuals have different abilities in reading their minds and looking at their environment.

Self-efficacy does not grow by itself, but is formed in the triangular relationship between personal characteristics, behavioral patterns and environmental factors (Bandura, 1997). Thus, this relationship is natural, personal and social, and it may require a long and complex process for creation. According to Bandura (1997), there are four sources of information that provide an important contribution to the formation of self-efficacy: (1) the experience of personal success (enactive mastery experiences), (2) experience of outcomes on others as a model (vicarious experiences), (3) praise and social rewards (verbal persuasion and other related social recognitions), and (4) a state of psychological and affective individual (physiological and affective states). The fourth source is what will be explored in this study to measure the level of self-efficacy of students in reading and writing foreign languages.

Basically self-efficacy is not specific to certain individuals because this is a general concept. Bandura (1997) argues that self-efficacy is the ability of the public consisting of aspects of cognitive, social, emotional and behavior, and the individual must be able to process these aspects in order to achieve certain goals. He cautioned that self-efficacy is a multi-purpose instrument for this concept not only relates to the ability, but also able to gain confidence that the individual can do various things in various conditions. In other words, self-efficacy is acted as generators of human capabilities. Therefore, it is not surprising if one has a strong self-efficacy, then he or she is motivated and even showed extreme view in the face of a situation.

\section{Teacher Efficacy}

Studies on teacher self-efficacy have largely been conceptualized within Bandura's (1994, 2002) notion of selfefficacy. Teacher self-efficacy has been defined as the extent to which a teacher is confident enough to his or her ability to promote students' learning (Bandura, 1994). According to Bandura, human behavior is motivated by the interaction of two kinds of expectations: self-efficacy and outcome expectancy; the former referring to peoples' judgments of their capability to undertake and successfully execute a specific task in a specific context, and the latter judgments about the consequences that this performance would bring about.

Smylie (1989) recognized that teachers with high self-efficacy are much more likely to provide opportunities for student communication by using a variety of models to meet the needs of all learners (working individually, in pairs, and in groups). Also a research has substantiated that teachers with high levels of self-efficacy are more likely to divide the class into small groups rather than teaching the class as a whole, thereby allowing the opportunity for more individualized instruction (Tschannen-Moran, 2001). Thus, it can be concluded that teachers with high self-efficacy allows providing a better learning process.

\section{Indonesian Teacher Education and New Curriculum as the Research Context}

Indonesia has modified its course of study 10 times from 1947 KTSP (School Level Based- Curriculum). Ministry of education and culture of Republic of Indonesia has already revealed the new course of study for Indonesia's education. It's known as the 2013 course of study. The implementation of the 2013 course of study has some effects in many ways in which somehow. The results should be in positive or negative. The benefits square measure the nice normal ability, the constructive approximation technique, and therefore the continued ability from elementary school to SMA (high school). Firstly, the graduation normal ability is regular. Per KTSP, the themes had to be fastened to take care of it. On the contrary, the 2013 course of study, the determination of graduation normal ability had to be fastened initial before the themes. Secondly, the 2013 course of study completes the approximation technique supported the students' ability. The new course of study fulfils 3 main parts of education: information, skill, and perspective. Information is evidenced by the lesson generally. Talent is from their sensible lesson like sports and perspective is mirrored by implementing the extra time for faith subject. seeable of character building and faith subjects square measure inserted into the 2013 course of study a lot of. The 2013 course of study is meant endlessly from elementary school to SMA. Specifically, the SMA ability could be a continuance from elementary school and secondary school (SMP).

In this regard, the government ought to specialize in making ready several things to implement the new course of study. A minimum of there are square measure 3 vital things should be fastened. They're the textbook, teacher training; education governance. The foremost important preparation is that the textbook. If the course of study is revised, and therefore the textbook is unchanged, as a result the new course of study can appear as if an impotency. It suggests that one thing that appears as threatening as a tiger, however doesn't stand up to a challenge. The government ought to prepare supply books for academics and students, and in fact each contents square measure completely different. Following distinguished readiness is academics coaching. During this case the implementation of the course of study is 
completed stage by stage that the teacher coaching also will be applied endlessly. If the implementation starts from the first grade, the fourth grade, the seventh grade, and therefore the tenth grade, a minimum of the academics National Examination (UN) agency can be a part of just about five hundred.

The last eminent issue that should be fastened is that the education governance. The ministry has meant the stage of the education governance. For that reason, the education governance for the 2013 course of study is additionally adjusted like the report administration book. Surely, ever-changing the course of study can modification four aspects: the content standards, method standards, graduation standards, and assessment standards. If four standards within the KTSP square measure modified in order that the report administration book, all of those changes mean that the new course of study very wants a giant set-up to be done by the government.

Therefore between KTSP and therefore the 2013 course of study create some variations and resemblances. It will be an honest facet and a nasty facet so. So as to manage the surprising impacts, well-preparation of the government is totally required. The implementation of 2013 course of study has round-faced several polemics. If the 2013 course of study is enforced in within the 2013/2014 school year, the government, teachers, and each person enclosed should support the modification by doing significantly in their own authorities.

While imposing many changes in the learning process from the previous curriculum, the government implemented it after only a one-year trial. Meanwhile the 2013 curriculum had the noble goal of imparting real-life knowledge to students it was a total failure in its implementation. As with any curriculum, teaching literature at school definitely oriented literary knowledge and literary appreciation. That orientation can be lowered to knowing, doing, and being literary; appreciation, expression, and production of literature; or can be formulated in terms of understanding, doing, and enjoying literature, all of which can be contextualized more widely, can be discussed with other texts. Whereas some of investigations have identified consistent relationships between teachers' efficacy beliefs and certain antecedent factors, researchers not yet to understand fully the connection between school context and efficacy beliefs. For example, many of the studies examining this relationship still inconsistent results.

Moreover, whereas researcher investigated the relations of contextual factors to teacher efficacy beliefs, few (if any) examine possible mechanisms that might mediate or explain these relationships. The purpose of this study was two-fold: The purpose was to examine what is the level of teachers efficacy, how is teacher efficacy related to experience level, beliefs about ability, what interaction happens between teachers' efficacy toward their performance - a factoral analysis, and whether there is any influences of teachers' efficacy and their performances.

\section{METHODS}

In particular, this study aimed to identify teacher perceptions about their own teacher self-efficacy for teaching literature within the New Curriculum framework; their performance in teaching literature related to their years of teaching experience; and their self sense of efficacy associated with their beliefs about students' ability. The variable studied these perceptions measured using an open-ended and semi-structured interview. Data for a phenomenological study is collected by a number of methods, such as interviews and observation. Kvale and Brinkmann (2009) stated: "In focusing the interview on the experienced meanings of the subject's life world, phenomenology has been relevant for clarifying the mode of understanding in a qualitative research interview". The interview method was chosen as it encouraged discussion about teacher experiences with their teaching process. The reason to use individual semistructured interviews as this was the best method to gather data on each individual's personal attitudes and perspectives.

Generally, qualitative interviews attempt to allow researchers to understand the world from their participants' points of view and also to unfold the meaning of people's experiences, as well as to uncover their lived world based on scientific explanations (Bogdan \& Biklen, 2006; Kvale \& Brinkmann, 2009; Merriam, 2007). Therefore, in this paper, it tried to explain how participants from a particular context experience having a gifted and talented child in their life. Hence, interviewing the participants seemed to be the most appropriate method to achieve this objective.

The target population for this study is the secondary public school teachers who taught students in grade 9 through grade 12 in two high schools - Private High School (SMA) - in Kendari. The subject was 5 teachers of 12 total teachers involved themselves voluntarily. Before the study is done, all the teachers asked to sign a consent form for data collection.

An interview conducted in the form of an open interview on 5 teaches at the time when the teacher does not have a teaching schedule. All the answers or their statements recorded on audiotape. The questions raised related to the planning, implementation, evaluation of learning and performance improvement activities of professional teachers at school or outside of school. The audio recordings were then transcribed. Classroom observations also conducted to strengthen the data collected through interviews, classroom observation is necessary to be done. This observation is focused on several activities of preparation of teachers teaching materials, classroom management involves asking questions, giving feedback and modeling, as well as the enthusiasm of the teacher during the learning process takes place.

\section{DISCUSSION}


In the following subsections, it presents the findings of the research questions in the order in which are presented above. Several key themes emerged from the data, firstly describe findings relating to teacher self-efficacy for teaching literature within the new curriculum framework, (research question 1); and then explain how the self-efficacy related to their teaching experience (research question 2); finally, present the teacher's self senses of efficacy associated with their beliefs about students' ability (research question 3).

\section{A. Teaching Literature within the New Curriculum Framework}

In the era of today's technology and communication, English as an international language has more dominant role. It can be predicted that quite a lot of students who would be interested to learn English more intensively by taking English language and literature subject. In the 2013 curriculum, the textbooks for interest-based class at senior high schools based on the core and basic competencies that have been issued by the Government of Indonesia. Based on the characteristics of curriculum, teaching materials are presented more in the form of activities to do student, either individually or in groups. Such activities are designed by considering the factors diversity of topics, situations, contexts, and appeal so that students are not easily bored, on the contrary they could learn in a pleasant atmosphere.

One of the data for example, teacher aware of one of the rules of 2013 curriculum that they mostly requires their prime professional challenge as developing their own subject matter and its pedagogies and establishing its relevance to their students, together with ensuring that they had the skills to implement the goals of the discipline in the question. It described as I (Interviewer) and R(espondent) as follows:

I: Do you follow the 2013 curriculum?

R1: "Yes, we follow the curriculum"...."we teach as usual as in the curriculum, there is already a class syllabus for interest-based class that is different from the regular one", however, R3 noted "Yes, I follow that curriculum. In 2013 curriculum, the involvement of the teacher is only $30 \%$, where $70 \%$ is done by the students themselves"; while R4 noted that "following to the 2013 curriculum, a classroom activity are 75 percent for students and 25 percent for teacher".

It indicated that the involvement of teacher in 2013 curriculum, students to be involved at least $75 \%$ in the learning process. But with regard to the teaching materials, teachers sometimes prepare materials or students allow to searching for their own materials.

I: Could you tell me about the available collections of literature for being tough and kinds of literary texts you use as teaching materials?

R1: "Actually it prepared not too prominent that schools are prepared, so teachers who initiated the search for literary material itself”, but R3 commented: “...learners much find materials by themselves or I just did some improvements in the materials to make students more interesting...., there are some kinds of English literature that I taught such as song, novel, drama and poetry.", while R4 said: "...only instructed what students have to prepare and then search for their own material.", and R5 noted: "The material is difficult to find because not many books available on ..., thus most students searching or browsing the internet."

It mostly described that teachers do not always use the material which is provided by school to teach the students in literature class, but sometimes when it is possible, ask students to prepare their own materials.

Concerned with the ways of the teachers delivered their lesson, teachers applied some strategies that attempt to be actively involved and try to find the right methods as cooperative learning which may in the different methods, such as discussion, peer group and other as noted as follows:

I: What strategies do you use to reach the target in learning?

R1: "I always do strategies in vary", $R 4$ noted that: "I applied in varies for example cooperative method. For strategy, I don't tick only one strategy because I worried if students get bored."

I: How about the method you apply?

R3: "I just focus on students' centered; therefore the learners much find materials by themselves."

I: How the way you applied that method?

R4: "Well, in managing small or big group discussion of students, I put them randomly.", while R5

noted: "I use a scientific approach, dominant by applying the student-centered and group discussions."

It seems that teachers try to have a direct influence on students to be connected with the students' minds. Teachers do not tick with only one strategy but use the same technique repeatedly. Moreover, in managing mall or big group of students, teacher put them randomly, so students grouped in small or big group discussion. It also avoid student dominating the small group.

By those statements above, it is good to support teacher and students need as the materials interesting for them, because it talks about story, poem, novel and others. Besides, it is based on their own choices because students choose materials based on their own interest. That is why, the learning environment more enjoyable for them since it is their own choice. Furthermore, the teachers try to make students more active in learning in which the students search for the learning material and put into students-active strategy. However, teachers do not give further information into what kind of technique the teacher uses other than that the technique is from cooperative learning method.

B. Teachers' Self-efficacy and Teaching Experience 
The finding is in line with teachers' self-efficacy concerning with their professional identity or teaching experience. As in the curriculum of 2013, English language and literature be one option as an interest-based class. In handling the class, one of teacher faces many challenges in applying the teaching literature. Therefore, teachers in the interest-based class asked if must or not to be trained before the school decides to apply the syllabus or lesson plan. Here is how one teacher educator described the resistance:

I: Before starting to teach in interest-based class, is there any special training for teachers before teaching literature?

R1: "No special training. We teach as usual as in the curriculum, there is already a class syllabus for interest-based class that is different from the regular one, while R3 noted: "Actually, I have been trained before are allowed to teach English literature class", and R4 said: "Yes, It must be. I got a kind of training."

In accordance with applyng the syllabus or lesson plan, not all teachers follow a kind of training. The reason that course syllabus already provided for interest-based class, in terms of the teaching and learning process they teach adjusted with signs of syllabus. Teacher made it clear that they could plan, develop, and implement their teaching according to their own intentions and wishes. This also seems to be the situation in handle English language and literature class with 20 to 30 students in it. Techers described this as follows:

I: How many students you teach in English language and literature class?

R1: "30 student", while R2 said: "There are 23 students", and R3 noted: "It consist of 20 students", but R4 said: "34 students for 2 classes"

The total student is categorized as effective classroom since his classroom is consist of 20 students. Logically, because English literature class based on students own choice; therefore it is real interest-based class which means students must be face different motivation with one of literary fields, whether it is drama, poetry, or novel. Teachers described their thoughts as follows:

I: How do you motivate your students in teaching literature?

R4 argued: "Because my job is teaching, so I must fulfill it. Students choose English class, means it based on their own motivation on their interest over the subject of literature. So, I determine the students' motivation from what they have chosen among other optioning classes."

I: Let me know then, how do you see the students' motivation in learning literature.

R3: "Students are motivated to choose and learn English through literature in this interest class. It can be analyzed through the total students. I only teaches 20 students even the others have more."

It simply that teachers motivated their students to choose and learn English through literature in this interest class. The reason may through the total students small class size only 20 students. However, in the process of teaching the students to analyze the text, teachers should experience themselves in deliver how to appreciate the literary works as the following descriptions:

I: So, what kinds of literary texts you use as teaching materials? Let me know in details.

R3: There are some kinds of English literature that I taught such as song, novel, drama and poetry. In the process of learning, I share some materials. For example in the teaching of song, I ask students to find song, and then analyze it. But sometimes I found a song by myself then analyzed it together through the involvement of technology such as LCD projector.

I: So, how about teaching short story?

R3: "Well, short story is the easiest part of teaching literature. This is because the stories are always interesting for them."

I: So how about prose fiction or drama?

R3: 'Oh, you mean students' appreciation of novel, it is quite hard to involve the learners in the real reading of novel since the time allocation is limited and the numbers of pages of novel are quite a lot to be learned in the classroom. While teaching of drama is quite different, because I apply the role play."

In the process of analyzing above types of literature, teacher did not involve the learners in the experience of real analysis. He only taught them the theory about analyzing those kinds of English literature, but sometimes he involved students with only the simple analysis, such as intrinsic elements. It can be argued that this is because the capacity of the learners which is of course different with the capacity of the university students. He doesn't think that his learners will be able to do that.

\section{Teachers' Self-efficacy and Their Beliefs about Students' Ability}

In line with teachers' self-efficacy concerning with their beliefs about their students ability, respondent 1 (R1) argues about the assessment or the evaluation she applied:

I: What about the assessment? I mean, the evaluation method used

R1: Assessment used in this school is adapted to the assessment guidelines ... for example if there is a

novel task, they look for themselves then asked to find anything in the novel.

I: So according to you, is more prominent for those who took literature classes. 
R1: Yes ..., they are more prominent participating in interest-based class ... they intensively studied literature because it was their chosen majors. But generally in a class he will be dominant in the following literature lesson so the results will vary.

It means that, she uses two kind of assessment; written test or oral performance. She uses both of the types to assess students' comprehension in novel, drama, poetry, and so on. She uses the assessments that seem appropriate with the course. While respondent 3 (R3) argues if he allows students to know how to analyze the instrinsic element elements of literary work:

I: Do they analyze those types of literary works? I mean all the elements.

R3: I didn't involve the learners in the experience of real analysis. I only taught them the theory about analyzing those kinds of works. It because the capacity of the learners which is of course different with the capacity of the university students. I don't think that our students will be able to do that. Even, sometimes I involved them with only in the simple analysis, such as intrinsic elements.

In the teaching process, he only asks the students to find simple literary works then analyzed it together through the involvement of technology such as LCD projector.

\section{CONCLUSION}

In relation to this, most teachers said in interviews that they were applying some teaching approaches for example, applying the method of cooperative learning approach although it takes a lot of time in preparation. It is understandable that teachers have to bear the burden of a heavy curriculum in the education system in this country.

Based on the results of the qualitative data processing discovered important things that need attention. Self-efficacy of teachers does not have an impact when applied in practice teaching. These findings can be interpreted to mean that the teacher should demonstrate behaviors that reflect the elements of self-efficacy.

In the classroom observation, these elements are generally not appear even teaching approach was not indicated as when the process of cooperative learning, teachers do not demonstrate efficacy themselves by observing and following the discussion process of students in the learning process. In this case, during the interaction of group discussions in the classroom, the teacher should monitor the process of group discussion. So, it appears if there is no missing link between what is believed, said and practiced by the teacher.

Classroom observation results showed that reliance on textbooks is not accompanied by an increase in the ability of teachers to ask questions to the students during the learning process. Basically, the diversity of questions can provide more opportunities and experiences for students to learn a variety of things. Most of the questions asked only in the low cognitive level (recall or rote) by the teacher. However, most of them give time to the researcher to conduct classroom observations showed great enthusiasm. The enthusiasm is shown by a variety of feedback and reinforcement needed by students and countenance reasonable, physical movement, and seriousness during the learning process, although there are some teachers who looked stiff, cold and may be "disturbed" by the presence of researchers in their classroom ,

There are several conclusions that can be drawn in this discussion. Firstly, teachers may intentionally or unintentionally exaggerate their state of self-efficacy in order not to lose face in the eyes of others because they are not familiar with the practice of self-assessment that the self-assessment is not conducted objectively and realistically. Secondly, the research instrument used to measure self-efficacy was not able to quantify what exactly should be measured in spite of all the instruments have been processed through the validation process. Finally, there may be a "mismatch" between the cultural aspects of self-efficacy. However, efforts to find and identify what was in the minds of teachers must still be done to improve the quality of teachers and the quality of student learning. Based on the results of scanning the literature available in a variety of sources, this study is an attempt to document the state of self-efficacy of teachers in teaching the material literature in English language teaching at the level of high school, but this study will be more beneficial and has external validity high if followed up with research next.

\section{ACKNOWLEDGEMENTS}

Thanks to the Directorate General of Resources for Science, Technology and Higher Education which has provided the funding in conducting this study. Thank you is addressed to Prof H. Mansur Akil, M.Pd. and Prof. Basri Jafar, Ph.D. at State University of Makasar, Indonesia and thank you very much for the contribution and supervision Corrine M. Wickens, Ph.D at Literary and Elementary Eucation at NIU, DeKalb Illinois USA

\section{REFERENCES}

[1] Bandura, A. (2006). Guide for constructing self-efficacy scales. Self-efficacy beliefs of adolescents, 5, p.307-337.

[2] Bandura, Albert .(1986). Social Foundations of thought and action: a social cognitive theory. New Jersey: Englewood Cliffs, Prentice.

[3] Bandura, Albert. (1997). Self-Efficacy: The Exercise of Control. W.H. Freeman and Company, New York.

[4] Billingsley, B. S. (2004). Special education teacher retention and attrition a critical analysis of the research literature. The Journal of Special Education, 38(1), p.39-55. 
[5] Brouwers, A., \& Tomic, W. (2000). A longitudinal study of teacher burnout and perceived self-efficacy in classroom management. Teaching and Teacher education, 16(2), p.239-253.

[6] Chairani, N. (2015). 2013 Curriculum Reflected in an International Oriented Senior High School, Yogyakarta. Sino-US English Teaching, 1 2(8), p.568-574.

[7] Coladarci, T. (1992). Teachers' sense of efficacy and commitment to teaching. The Journal of experimental education, 60(4), p.323-337.

[8] Goddard, R. D., Hoy, W. K., \& Hoy, A. W. (2000). Collective teacher efficacy: Its meaning, measure, and impact on student achievement. American Educational Research Journal, 37(2), p.479-507.

[9] Guskey, T. R., \& Passaro, P. D. (1994). Teacher efficacy: A study of construct dimensions. American educational research journal, 31(3), p.627-643.

[10] Hoy, A. W. (2000, April). Changes in teacher efficacy during the early years of teaching. In annual meeting of the American Educational Research Association, New Orleans, LA.

[11] Mills, N. (2011). Teaching Assistants' Self-Efficacy in Teaching Literature: Sources, Personal Assessments, and Consequences. The Modern Language Journal, 95(1), p.61-80.

[12] Pajares, F. (1996). Self-Efficacy Beliefs in Academic Settings. Review of Educational Research, Vol. 66(4), p.543-578.

[13] Tschannen-Moran, M., Hoy, A. W., \& Hoy, W. K. (1998). Teacher efficacy: Its meaning and measure. Review of educational research, 68(2), p.202-248.

[14] Zimmerman, B. J. \& Schunk, D. (1990). Self-regulated learning and academic achievement: An overview. Educational Psychologist, 25, p.3 - 17.

Nurindah is a senior lecturer of English Literature to the Department of English Education at Halu Oleo University, Kendari, Indonesia. Her research interests include classic and contemporary literary study, students and teachers/lecturers' self-efficacy, and teaching English as a foreign language.

Mansur Akil is a Professor in Translation and Language Teaching at State University of Makassar, Indonesia. He is a Senior lecturer on Language Philosophy, Theory Construction and Model Building, Translation, Systems Theory, and Research Methodology.

Muhammad Basri Jafar is a Professor in Applied Linguistics at State University of Makassar, Indonesia. His research interests deal with biliteracy development and bilingualism, English Language Teaching and Learning. 